\title{
Migration and precipitation of soluble species during drying of colloidal films
}

\author{
Pär Wedin ${ }^{\mathrm{a}, \mathrm{b}}$, Lennart Bergström ${ }^{\mathrm{a}, \mathrm{c}, *}$ \\ a YKI, Institute for Surface Chemistry, P.O. Box 5607, SE-114 86 Stockholm, Sweden \\ ${ }^{\mathrm{b}}$ Department of Chemical Engineering, Karlstad University, SE-651 88 Karlstad, Sweden \\ ${ }^{c}$ Department of Physical, Inorganic and Structural Chemistry, Stockholm University, SE-106 91 Stockholm, Sweden
}

Received 29 March 2004; accepted 6 August 2004

Available online 9 September 2004

\begin{abstract}
The evaporation-induced convection resulted in a transport of dissolved species, a water-soluble polymer (carboxymethylcellulose) and dissolved $\mathrm{CaCO}_{3}$, to the drying front of silica and $\mathrm{CaCO}_{3}$ dispersions where the material eventually precipitates. Scanning electron microscopy and chemical analysis showed that the concentration of carboxymethylcellulose, CMC, is highest in the centre of the dried silica film and decreases towards the perifery. The colloidal films of the monodisperse silica particles displayed a high degree of structural order even at high concentrations of the non-adsorbed polymer CMC, which suggests that any depletion induced interparticle attraction is insufficient to affect the assembly of the colloidal crystal. The $\mathrm{CaCO}_{3}$ particles are slightly soluble and we found that rod-like crystals reprecipitated in the centre of the particle films on top of the polyacrylate-coated particles. Addition of CMC disturbs the formation of distinct crystal shapes which was attributed to a complexation of $\mathrm{Ca}^{2+}$ in solution.
\end{abstract}

(c) 2004 Elsevier Inc. All rights reserved.

Keywords: Migration; Precipitation; Structure; Silica; $\mathrm{CaCO}_{3}$; Colloidal stability; $\mathrm{CMC}$; Carboxymethylcellulose; Polyacrylate; NaPA

\section{Introduction}

Colloidal films can be produced in a variety of ways, e.g., by spreading the particles at an air-liquid [1] or a liquidliquid interface [2]. The most common method of forming colloidal arrays is by deposition and controlled drying of colloidal suspensions onto a substrate [3-6]. This method is based on the convective assembling technique, where the capillary induced flow will transport particles from the dispersion to the drying front [7-9]. The method has been used to create large and well-ordered colloidal crystals in both three and two dimensions $[5,10]$. The capillary-induced liquid flow may also induce an accumulation of dissolved species at the drying front [11-14] and it has been sug-

\footnotetext{
* Corresponding author.

E-mail addresses: par.wedin@surfchem.kth.se (P. Wedin), lennartb@inorg.su.se (L. Bergström).
}

gested that the migration and precipitation of dispersed and dissolved species can result in inhomogeneities and structural defects in the colloidal films $[12,15,16]$. It is clear that the redistribution and precipitation of soluble salts and soluble organic additives - common constituents in, e.g., paper and board coatings [17-19], paint films [20,21], and ceramic coatings $[22,23]$ - can have important consequences for the optical and mechanical properties of these industrially important products.

We have studied how a water-soluble polymer (carboxymethylcellulose) and dissolved $\mathrm{CaCO}_{3}$ migrate and precipitate during drying of a dilute colloidal dispersions. The structural features of monoparticulate films of spherical silica particles have been compared to the structure of particle films of a commercial, polydisperse precipitated calcium carbonate powder using scanning electron microscopy. Carboxymethylcellulose (CMC) is a common additive in paper coatings [19], and it is of interest to determine how the 
structure of particulate films is influenced by the redistribution and precipitation of this soluble polymer because the structural features, e.g., the pore size distribution and the presence of large defects, have a strong effect on the print quality. We show that the dissolved species migrate towards the drying front, which induces a non-homogeneous distribution of precipitates in the dry film. The morphology of the reprecipitated $\mathrm{CaCO}_{3}$ varies from rod-like to equiaxial, which was related to the specific interaction of the $\mathrm{Ca}^{2+}$ ions with the organic additives.

Snowden et al. have shown that CMC does not adsorb on silica and may destabilize a colloidal silica dispersion by a depletion flocculation mechanism $[24,25]$. We were interested to establish if this type of polymer induced attraction would influence the structure of the particle films during drying. Our previous work showed that even a small amount of salt in the dilute dispersion can induce an aggregation of the particles during drying that has a significant effect on the structural features of the colloidal films [3]. That study found that the degree of order of the monoparticulate films decreased, and the concentration of large defects increased, with increasing amounts of added salt. However, we were unable to detect any significant reduction in the degree of order for the monodisperse silica films even at high CMC additions.

\section{Materials and methods}

\subsection{Materials}

Colloidal films were produced from two different powders, $\mathrm{SiO}_{2}$ and $\mathrm{CaCO}_{3}$. The spherical silica particles (Tokuyama Soda Co., Tokyo, Japan) were almost monodisperse with a mean particle diameter of $1.70 \mu \mathrm{m}$ (standard deviation $0.07 \mu \mathrm{m}$ ) as measured using scanning electron microscopy (Philips XL-30 ESEM, Eindhoven, Netherlands). The precipitated $\mathrm{CaCO}_{3}$ particles (Albaglos L PCC, Specialty Minerals, USA) were obtained from the manufacturer as a dry powder with a number mean particle size of $0.84 \mu \mathrm{m}$ with $90 \%$ of the particles finer than $1.5 \mu \mathrm{m}$ (Fig. 1), as determined by light scattering (Mastersizer 2000, Malvern Instruments). The specific surface area of the $\mathrm{CaCO}_{3}$ was $\sim 4.0 \mathrm{~m}^{2} / \mathrm{g}$, as determined by nitrogen gas adsorption (Model ASAP 2400, Micrometrics). X-ray diffraction showed that the $\mathrm{CaCO}_{3}$ powder consists of calcite; no aragonite or other oxides could be found. Carboxymethylcellulose (CMC, Finn-Fix 10, Metsä Specialty Chemicals Oy, Finland), with a weight average molecular weight of $60,000 \mathrm{~g} / \mathrm{mol}$ and a polydispersity of $\sim 4.0$, served as the water-soluble polymer. Sodium polyacrylate (NaPA, Dispex N40, Ciba Specialty Chemicals, Switzerland) weight average molecular weight of $3500 \mathrm{~g} / \mathrm{mol}$ was used as dispersant for the $\mathrm{CaCO}_{3}$ particles.

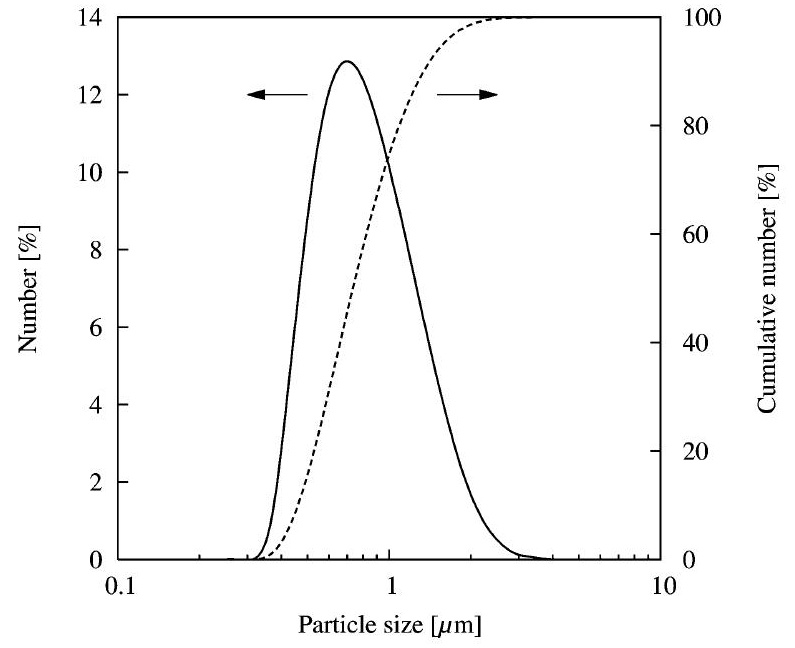

Fig. 1. The number particle size distribution for the $\mathrm{CaCO}_{3}$ powder.

\subsection{Methods}

The drying studies were performed in a simple cell consisting of a paraffin block with a hole $(d=4 \mathrm{~mm})$ attached to a glass substrate $[3,4]$. The $5 \mathrm{~mm}$ thick paraffin block (m.p. 346-353 K) was attached to the glass substrate by simply heating the block and the substrate at $363 \mathrm{~K}$ for about a minute and then gently applying some pressure on the paraffin block.

The silica particles were cleaned five times in filtered, double-distilled water with the centrifugation-decantation method. The cleaned particles were added to water and the dispersion was ultrasonicated for a period of $20 \mathrm{~min}$ (with a $5 \mathrm{~s}$ on/off pulse, Sonics Vibracell VC750. Sonics\&Materials Inc. Newton, CT, USA). The $\mathrm{pH}$ was varied between 7 and 9. Different amounts of the soluble polymer, CMC, were added and the dispersions were ultrasonicated for 20 minutes again. All the silica dispersions were used immediately after preparation.

The $\mathrm{CaCO}_{3}$ dispersions were prepared by first mixing the dispersant (sodium polyacrylate, $\mathrm{NaPA}$ ) with the as-received $\mathrm{CaCO}_{3}$ powder and the water, and the dispersion was ultrasonicated for $15 \mathrm{~min}$. The $\mathrm{CMC}$ was then added and the dispersions were ultrasonicated for another $15 \mathrm{~min}$ and stored for one week under gentle stirring in a closed container. The $\mathrm{Ca}$ ion concentration in solution was determined using ICPAES. The $\mathrm{pH}$ of the $\mathrm{CaCO}_{3}$ dispersions reached a value of 10 after one week of stirring. The dispersions were ultrasonicated before use to ensure that the particles were fully dispersed. The dispersion formulations are summarized in Table 1.

The initial volume fraction of solids and the applied volume $(V=12 \mu l)$ of the dispersion was chosen so that there were enough particles to cover the substrate in the cell with a monolayer of particles. The dispersions were dried at room temperature $(296 \pm 1 \mathrm{~K})$ and at a constant relative humidity of $30 \% \mathrm{RH}$. The relative humidity was controlled by a large reservoir of saturated $\mathrm{CaCl}_{2}$ solution in the drying 
Table 1

The composition of the dispersions used in the drying studies

\begin{tabular}{|c|c|c|c|c|c|c|}
\hline Sample & $\phi(\%)$ & Silica (wt\%) & $\mathrm{CaCO}_{3}(\mathrm{wt} \%)$ & $\mathrm{NaPA}\left(\mathrm{wt} \% \times 10^{-3}\right)$ & $\mathrm{CMC}\left(\mathrm{wt} \% \times 10^{-3}\right)$ & $\mathrm{CMC} /$ particle ratio \\
\hline 1 & 0.1 & 0.20 & 0 & 0 & 0 & 0 \\
\hline 2 & 0.1 & 0.20 & 0 & 0 & 1.36 & $6.8 \times 10^{-3}$ \\
\hline 3 & 0.1 & 0.20 & 0 & 0 & 2.71 & 0.0136 \\
\hline 4 & 0.1 & 0.20 & 0 & 0 & 5.42 & 0.0271 \\
\hline 5 & 0.1 & 0.20 & 0 & 0 & 13.6 & 0.0676 \\
\hline 6 & 0.1 & 0 & 0.27 & 0.81 & 0 & 0 \\
\hline 7 & 0.1 & 0 & 0.27 & 0.81 & 1.36 & $5.0 \times 10^{-3}$ \\
\hline 8 & 0.1 & 0 & 0.27 & 0.81 & 2.71 & 0.0100 \\
\hline 9 & 0.1 & 0 & 0.27 & 0.81 & 5.42 & 0.0200 \\
\hline 10 & 0.1 & 0 & 0.27 & 0.81 & 13.6 & 0.0500 \\
\hline
\end{tabular}

chamber [26]. The paraffin block was detached from the substrate when all the water had evaporated and the substrate containing the colloidal film was placed upon an electron microscopy specimen stub. The colloidal film was coated with gold (Balzers SCD 050 Gold sputter) and studied in a scanning electron microscope (SEM) (Philips XL-30 ESEM, Eindhoven, Netherlands). The chemical analysis was performed using energy dispersive spectroscopy (EDS) (EDAX, NJ, USA).

\section{Results and discussion}

\subsection{Silica colloidal films}

Monolayers of the monodisperse silica particles were formed when a dilute dispersion was allowed to dry on the glass substrate in the drying cell. Fig. 2 shows a representative section of a colloidal film formed from a stable silica dispersion free from additives. Previous work has clarified that the formation of a colloidal monolayer on a substrate is a two-stage process involving nucleation and crystal growth [5,7] (see Fig. 3). The nucleus forms when the thickness of the fluid film is so thin that the particles become pinned to the substrate and the deformation of the liquid film induces an attractive immersion capillary force that pull the particles together [8]. We found, in accordance with Dushkin et al. [4], that the nucleus always forms in the centre of the cell because this is where the fluid film has the smallest thickness due to the shape of the meniscus. The dilute dispersion partially wets the cell wall, which results in a concave meniscus. When drying proceeds, there is a convective flow of particles to the nucleus, and the $2 \mathrm{D}$ colloidal grows from the centre towards the edge of the sample cell. In order to grow a well-ordered colloidal crystal, the particles must be transported to the nucleus at a sufficiently high speed to dominate over the Brownian motion [4], but slow enough to allow for particle rearrangement at the drying front [3]. We have used relatively dilute dispersions since the volume fraction of particles should not be too high to facilitate rearrangement and minimize heterogeneous nucleation. Fig. 2 shows that we are able to assemble colloidal

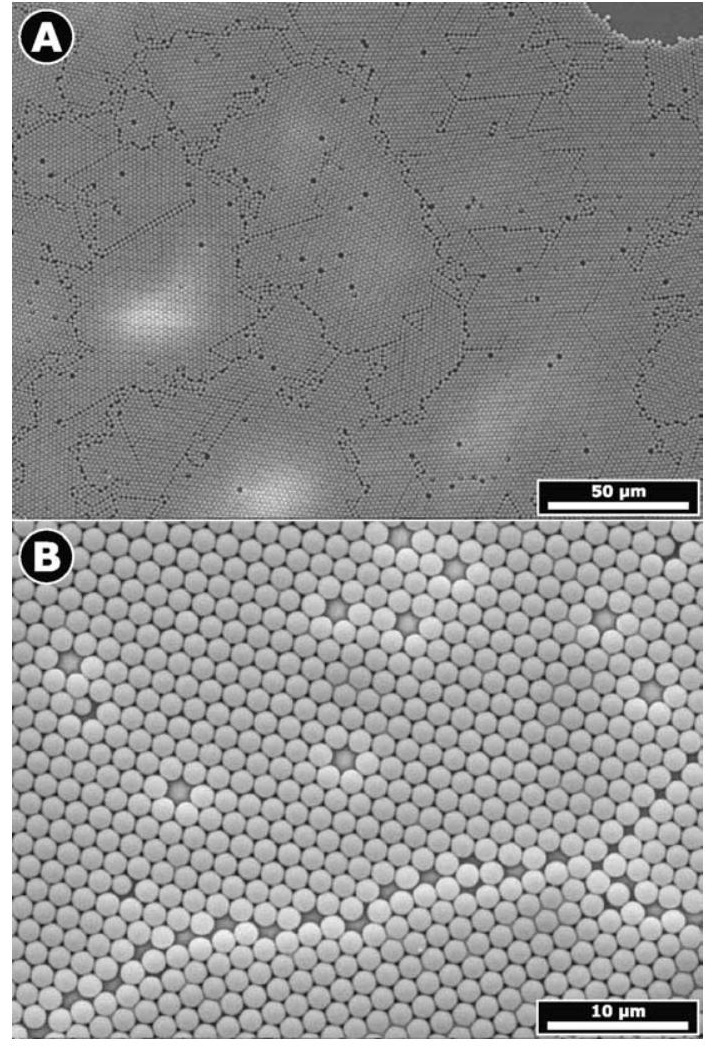

Fig. 2. SEM micrographs from the centre of a colloidal film formed from a suspension of monodisperse silica particles free from additives. Micrograph (A) displays the structure with large ordered domains and some defects and (B) displays a magnification where the typical defects; dislocations and missing particles, are clearly seen.

crystals with large ordered domains and only a small number of defects from the monodisperse silica dispersions. The repulsive interparticle forces ensure that the colloids are free to rearrange as they are transported to the growing colloidal film, where the immersion capillary forces [8] pack the particles into a hexagonal lattice. The most frequent defects are dislocations and missing particles (Fig. 2B).

The addition of a soluble polymer, carboxymethylcellulose (CMC), to the silica dispersion results in a well-ordered colloidal film. The SEM micrographs in Fig. 4 indicate that the soluble polymer is accumulated in the centre of the col- 

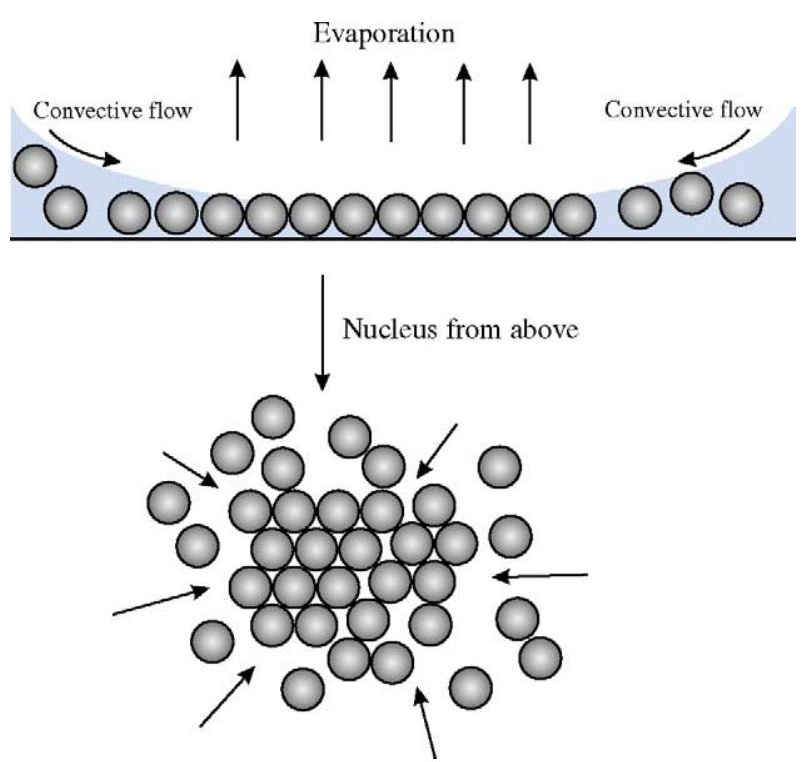

Fig. 3. Schematic figure of the evaporation driven nucleation and growth of a colloidal film onto a substrate.

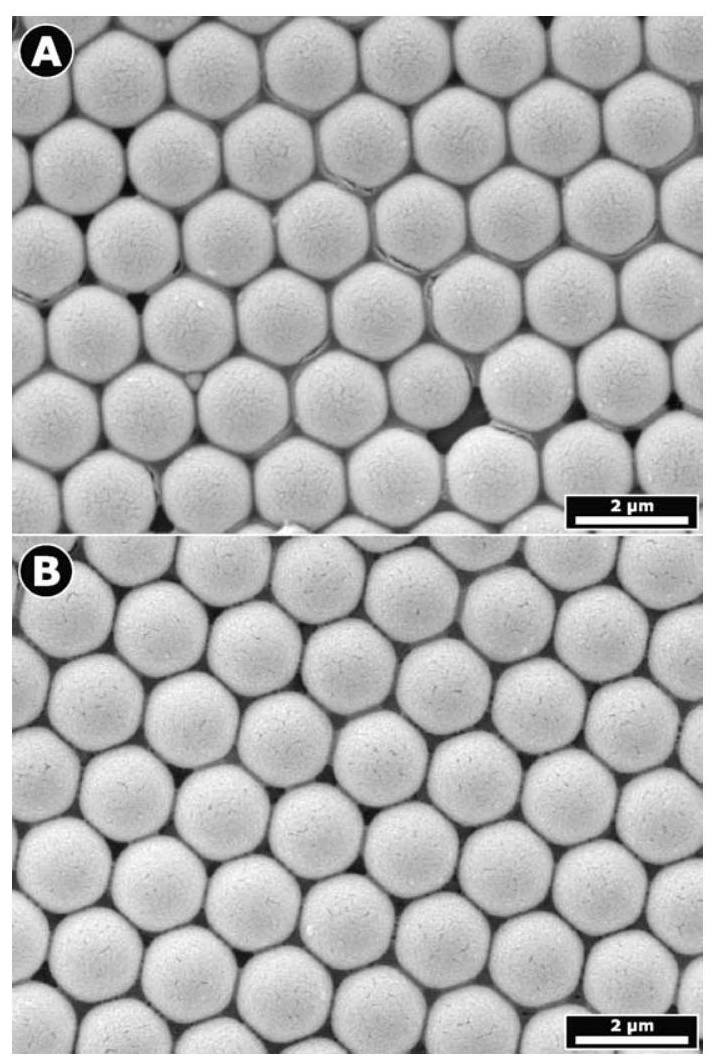

Fig. 4. SEM micrographs from the centre (A) and from the edge (B) of a dry colloidal film formed from a suspension having a $\mathrm{CMC} /$ silica ratio of $6.8 \times 10^{-3}$. The precipitated polymer can be observed in the centre of the film, whereas the edge appears to be virtually free of CMC.

loidal film while the edge of the colloidal film appears to be virtually free of CMC (Fig. 4B). The migration of dissolved species during drying of a colloidal film becomes more apparent as the amount of CMC increases. Fig. 5A shows that

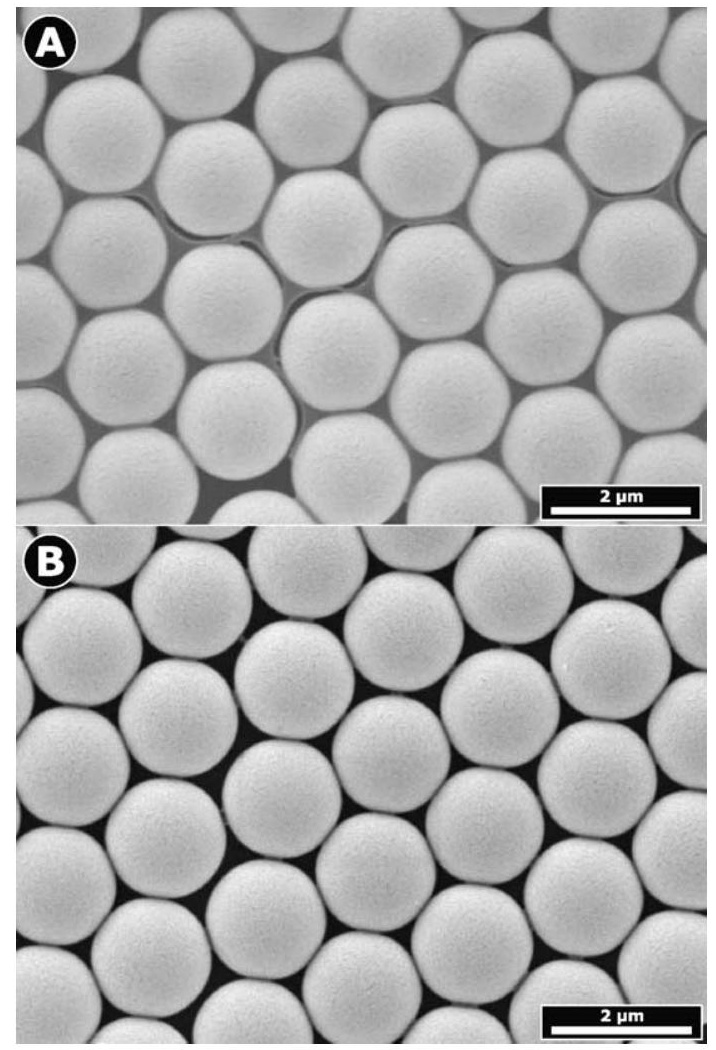

Fig. 5. SEM micrographs from the centre (A) and the edge (B) of a dry colloidal film formed from a suspension having a CMC/silica ratio of 0.0271 .

there is an abundance of precipitated polymer at the particleparticle and also at the particle-substrate contact points (not shown) in the centre of the colloidal film. In contrast, the edge of the colloidal film appears to be relatively free of precipitated polymer (Fig. 5B). The spatial distribution of the carbon content in the colloidal film was determined and the measurements confirm that $\mathrm{CMC}$ is enriched in the centre of the film and depleted at the edge (Fig. 6).

The micrographs and the chemical analysis measurements clearly show that the soluble polymer CMC is transported with the liquid to the drying front in the centre of the film where the polymer eventually precipitates as the water content becomes sufficiently low. The well-defined dimensions of the drying cell and the wetting of the cell walls ensure that the colloidal film always has a drying front that originates in the centre of the cell and moves outwards as the colloidal crystal grows. However, the drying front can also originate from the edge and grow inwards when a dispersion is applied on a flat substrate and allowed to dry. The colloidal crystal then nucleates at the three-phase contact line, i.e., at the edge of the dispersion drop, where the particles first become pinned to the substrate [12,27]. This results in a convective transport of particles and other dissolved matter from the centre towards the edge and the final result can be a ring of deposited material if the solids concentration is low, the so called coffee ring effect [27]. Studying the drying behavior of relatively concentrated dispersions, Guo and 

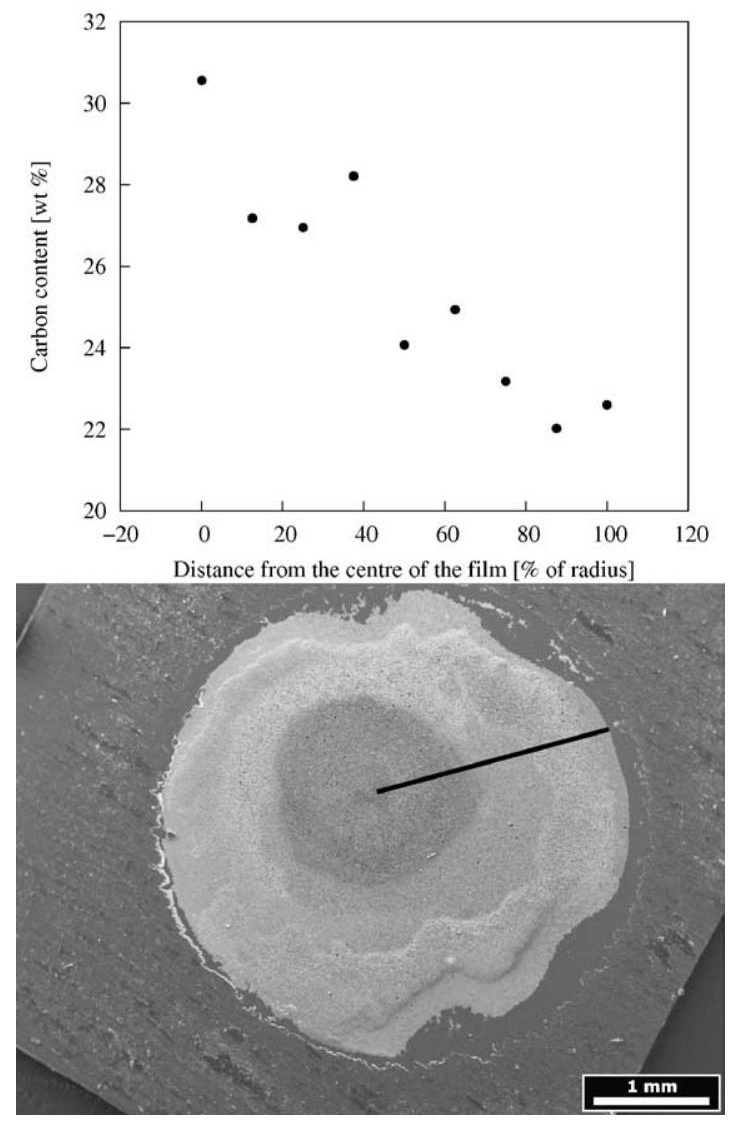

Fig. 6. The graph displays the concentration gradient of carbon in a colloidal film with an average $\mathrm{CMC}$ / silica ratio of 0.0676 . The line in the micrograph shows where the concentration gradient was measured.

Lewis [12] found that an added salt was transported to the edge of a colloidal coating that was applied on a substrate and allowed to dry.

Large cracks can be found in the centre of the colloidal film (Fig. 7A) formed from a suspension containing a large amount of CMC (CMC/silica ratio of 0.0676). It has previously been shown that films cast from polymer solutions can 


\section{2. $\mathrm{CaCO}_{3}$ colloidal films}

We have also studied the drying behavior of $\mathrm{CaCO}_{3}$ dispersions. The $\mathrm{CaCO}_{3}$ particles are irregularly shaped and have a broad particle size distribution. Calcium carbonate particles are inherently unstable due to a low negative surface charge [35]; hence, we have added sodium polyacrylate (NaPA) [36] to stabilize the suspension. Thin colloidal films have been assembled by drying dilute $\left(0.1\right.$ vol\%) $\mathrm{CaCO}_{3}$ suspensions following the same experimental protocol as was used for the dilute monodisperse silica dispersions. However, the structures of the $\mathrm{CaCO}_{3}$ and silica colloidal
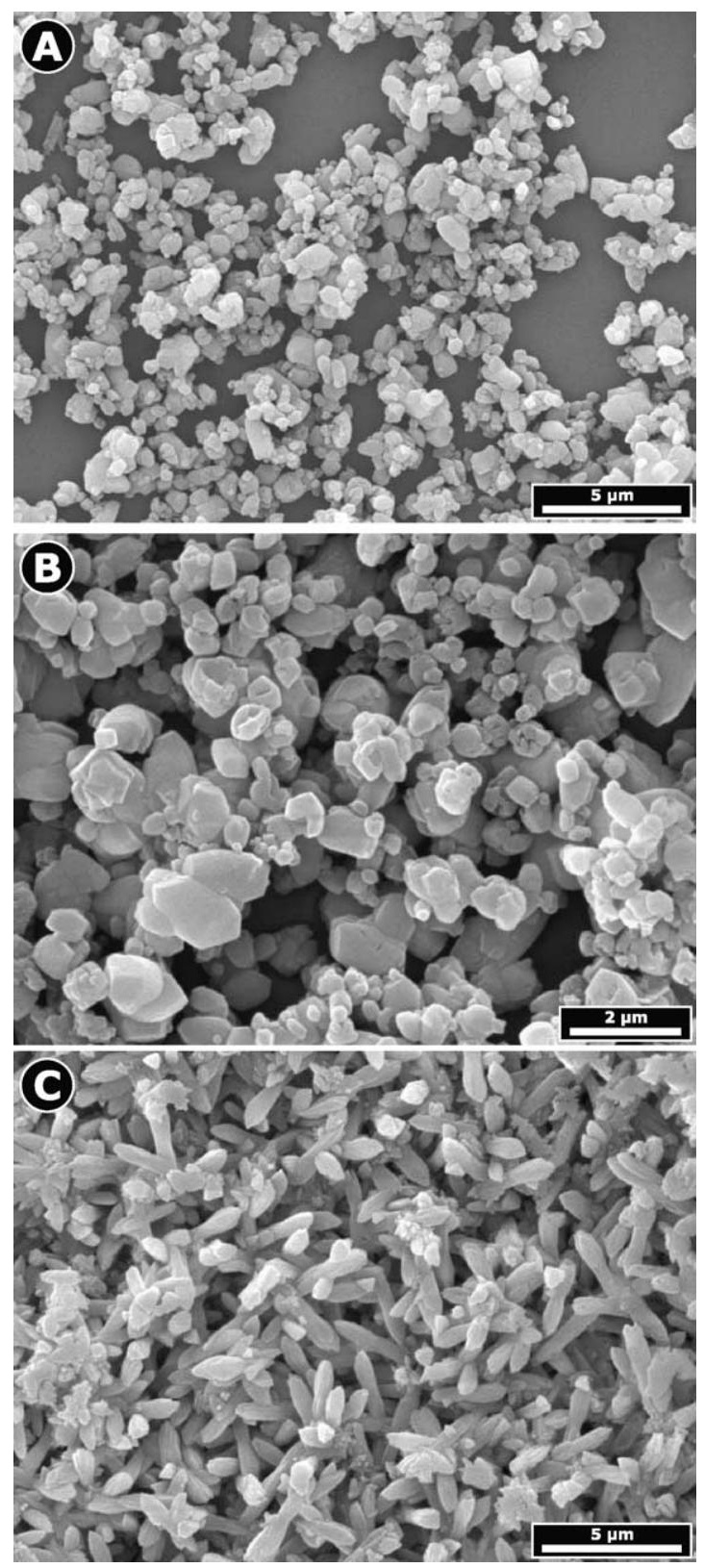

Fig. 8. SEM micrographs from of a particulate film formed from a $\mathrm{CaCO}_{3}$ suspension: (A) displays the edge of the film, (B) half way to the centre, and $(\mathrm{C})$ displays the centre portion. films differ greatly. The $\mathrm{CaCO}_{3}$ particulate films (Fig. 8) are highly inhomogeneous with a wide pore size distribution. There is also an apparent spatial distribution in particle density and layer thickness in the particle film (compare Figs. 8A and 8B). The irregular shape and wide particle size distribution of the $\mathrm{CaCO}_{3}$ particles obviously prohibit the formation of any long-range order in the particulate film. The wide particle size distribution will also cause particles to be pinned simultaneously at different positions on the substrate, which may result in a complex convective transport pattern when the film grows during drying. We speculate that this type of heterogeneous nucleation may explain the clusterlike appearance of the edge of the particle film shown in Fig. 8A.

The thickness and density of the particulate film increase towards the centre of the film, which indicates that the capillary induced assembly of these type of polydisperse and irregular particles results do not only occur laterally along the substrate but there is also a vertical component. It is clear that the rearrangement of the particles during film growth will be strongly inhibited by the irregular shape and it is possible that particles become pinned on top of other particles. Hence, the particles will assemble not only in the plane of the substrate but they may also form three-dimensional structures.

The particles in the central regions of the film (Fig. 8C) display a distinct rod-like shape, quite unlike the more equiaxial shape of the as-received powder; see, e.g., the edge of the particle film. There is a very well defined boundary at a short distance from the centre of the film, which separates the regions of the equiaxial and rod-like particles (Fig. 9). Closer examination of the micrograph in Fig. 8C shows that many of the rod-like particles originate from the surface of other, underlying particles. This suggests that the rod-like particles have not been transported and assembled to the centre of the particle film but have actually been formed from solution by a nucleation and crystallization reaction.

The $\mathrm{CaCO}_{3}$ dispersions that were used in these studied were prepared one week in advance and kept under gen-

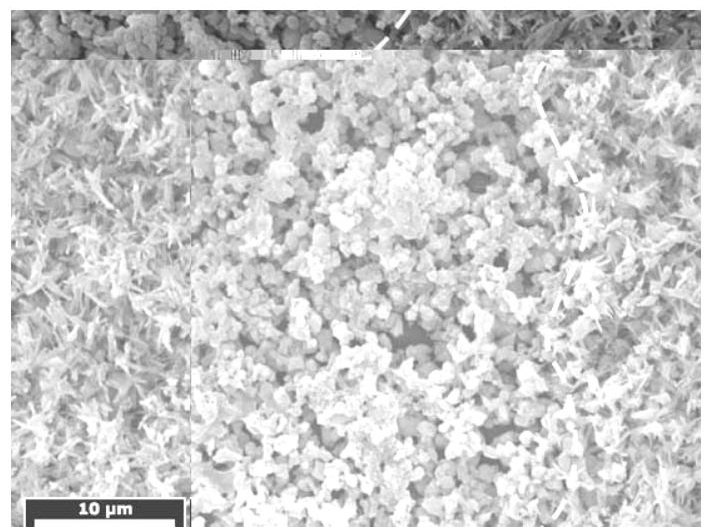

Fig. 9. SEM micrograph of the boundary (marked with a dashed line) between the zone with (right) and without (left) rod-like particles in the dried $\mathrm{CaCO}_{3}$ film. 
tle stirring before the dispersion was placed in the drying cell and the particle films were formed. It is well known that $\mathrm{CaCO}_{3}$ is slightly soluble in water and we determined the concentration of $\mathrm{Ca}$ ions in the dilute particle dispersions to be $0.23 \mathrm{mM}$. This initially low ion concentration will of course increase as drying proceeds and simple estimates suggest that the $\mathrm{Ca}^{2+}$ concentration has increased to more than $10 \mathrm{mM}$ when the thickness of the liquid film is $20 \mu \mathrm{m}$ (assuming a flat meniscus), which is sufficiently high to reprecipitate $\mathrm{CaCO}_{3}$ at $\mathrm{pH} 10$ [37]. This suggests that the rod-like particles originate from re-precipitation of dissolved $\mathrm{CaCO}_{3}$ that have been transported to the drying front. Similar to the transport of the soluble polymer in the previously investigated case, we expect that the dissolved $\mathrm{CaCO}_{3}$ will be transported to the central regions of the particle film by the capillary-induced transport mechanism. When the supersaturation of the dissolved material reaches a critical level, $\mathrm{CaCO}_{3}$ will nucleate and crystals will grow.

Previous work has shown that the formation of $\mathrm{CaCO}_{3}$ particles of various shapes is very sensitive to the nature and concentration of organic molecules in solution [38-40]. It is well known that there is a strong interaction between carboxylic acid groups and the crystallizing $\mathrm{CaCO}_{3}$ [41-45]. In a thorough study, Cölfen and Qi [37] showed that the morphology and size of $\mathrm{CaCO}_{3}$ crystals were mainly controlled by the $\mathrm{pH}$ and the concentration of an carboxylic acid-containing block-copolymer. They found that rod-like crystals could be obtained at room temperature when the experimental conditions favoured slow nucleation and subsequent crystal growth from a single nucleation site. Our observation that the rod-like crystals seems to originate from the surface of underlying particles suggests that it is the adsorbed sodium polyacrylate on the surface of the as-received powder that acts as the nucleation sites. Previous work has suggested that adsorbed polyacrylates may promote the nucleation by concentrating $\mathrm{Ca}^{2+}$ ions near the surface $[39,43]$. The evaporation-driven increase in the concentration of the dissolved $\mathrm{CaCO}_{3}$ limits the possibility of a burst a many nuclei simultaneously and may thus promote a sufficiently slow growth from the nuclei on the powder surfaces to yield rodlike crystals. We also performed a control experiment where particle films were prepared from $\mathrm{CaCO}_{3}$ dispersions that had not been stabilized with NaPA. These particle films were more inhomogeneous because of the poor colloidal stability but the general features were similar to those of the particle films in Fig. 8, except for the lack of any rod-like particles anywhere in the film (not shown). This supports the notion that the adsorbed polyacrylate is necessary to promote the reprecipitation of rod-like crystals. Reprecipitation in the absence of any polymer is expected to yield rhombohedral and equiaxial crystals [37], a morphology that is difficult to distinguish from the as-received powder.

We have also investigated the effect of addition of carboxymethylcellulose (CMC) on the $\mathrm{CaCO}_{3}$ particle films . The centre of the dried particle film (upper left corner of Fig. 10 and Fig. 11B) has lost much of its granular charac-

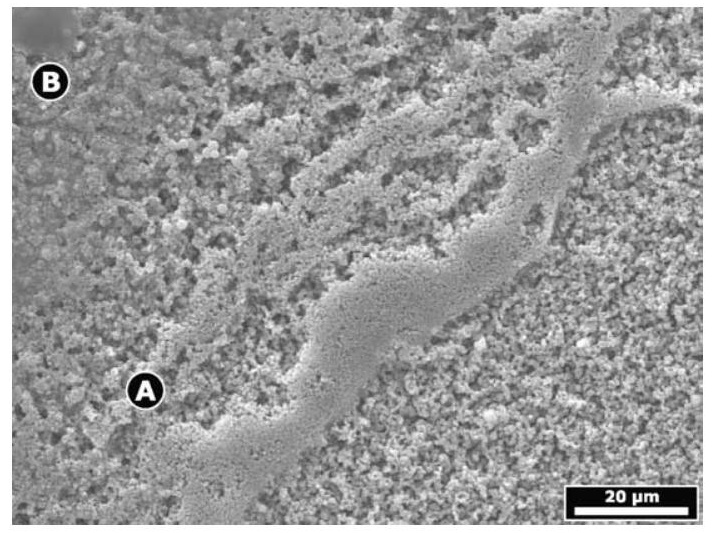

Fig. 10. SEM micrograph from a particulate film cast having a CMC/ $\mathrm{CaCO}_{3}$ ratio of $5.0 \times 10^{-3}$. The centre of the film is towards the top left corner. The letters "A" and "B" corresponds to the locations of the magnifications in Fig. 11A and 11B.
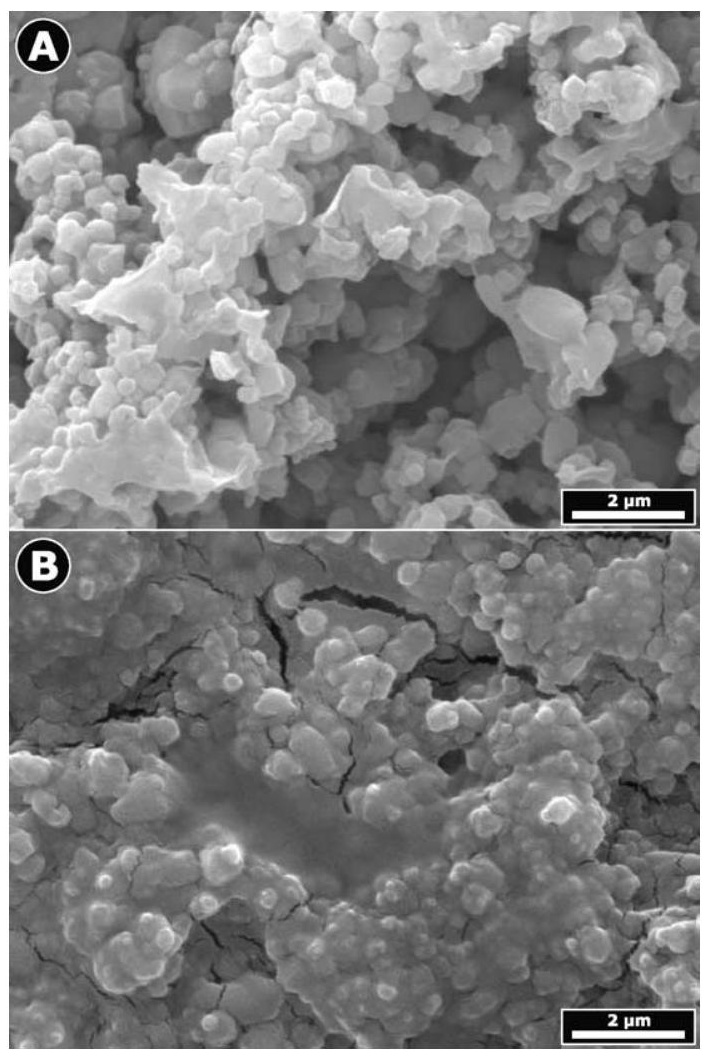

Fig. 11. Magnifications from Fig. 10. (A) displays the porous $\mathrm{CaCO}_{3}-\mathrm{CMC}$ film just outside the centre of the film and (B) displays the dense $\mathrm{CaCO}_{3}-\mathrm{CMC}$ film at the very centre of the particle film.

ter and seems to be coated with a polymer film; this suggests that $\mathrm{CMC}$ has migrated and precipitated at the drying front. There is almost no trace of any precipitated polymer at the edge of the particle film, in analogy with the distribution of CMC in the colloidal crystals formed from the monodisperse silica particles (Fig. 4). Fig. 11A shows a magnification of an area just outside the centre of the particle film where it is possible to identify some regions of precipitated material that bond the particles together. It is interesting to note that 
there is no evidence of any rod-shaped crystals anywhere in the colloidal film. This suggests that the addition of CMC has a significant influence on the morphogenesis of the reprecipitated crystals from the dissolved $\mathrm{CaCO}_{3}$.

Carboxymethylcellulose is an anionic polymer that contains carboxylic groups. Backfolk et al. [46] and Verraest et al. [47] have shown that CMC can form complexes with $\mathrm{Ca}^{2+}$, and we thus expect CMC to control the nucleation and crystal growth of $\mathrm{CaCO}_{3}$ in a similar fashion as the polyacrylates. Previous work has shown that CMC is not able to replace a preadsorbed polyacrylate from the surface of the $\mathrm{CaCO}_{3}$ particles [46]. Hence, it is plausible that the addition of $\mathrm{CMC}$ to a stabilised $\mathrm{CaCO}_{3}$ suspension results in a complex formation between $\mathrm{CMC}$ and the dissolved $\mathrm{Ca}^{2+}$ in solution. However, the conditions for controlled precipitation becomes quite complex as there is adsorbed polyacrylates on the surface of the powders and free CMC in solution and the concentration of dissolved $\mathrm{CaCO}_{3}$ and $\mathrm{CMC}$ varies both with time and position as the particle film grows. Zhang and Gonsalves [43] found that it is necessary to optimize the ratio between the adsorbed and the free polyacrylate in order to successfully precipitate continuous $\mathrm{CaCO}_{3}$ films. If the polyacrylate concentration in solution is too high, the polyacrylate will bind the $\mathrm{Ca}^{2+}$ and it is not possible to grow $\mathrm{CaCO}_{3}$ films. This suggests that the morphogenesis of the rod-like $\mathrm{CaCO}_{3}$ crystals in the dispersions free from CMC (Fig. 8) is not affected by the minute amounts of NaPA that may remain un-adsorbed. However, the addition of CMC disturbs the crystal growth process, thus limiting the possibility of the formation of distinct crystal shapes. With the relatively high $\mathrm{CMC}$ concentrations in solution, corresponding to a $\mathrm{CMC} /$ dissolved $\mathrm{CaCO}_{3}$ ratio above 80 , it is more likely that the precipitate is some sort of a $\mathrm{CaCO}_{3}-\mathrm{CMC}$ composite. Increasing the $\mathrm{CMC}$ addition increases the area of the dense $\mathrm{CaCO}_{3}-\mathrm{CMC}$ region, while the edges of the film particle remain practically free from precipitated polymer. The width and length of the cracks in the $\mathrm{CaCO}_{3}-\mathrm{CMC}$ film also increase, probably due to an increase in the induced drying stress with the amount of CMC.

\section{Summary and conclusions}

We have studied how the structural properties of colloidal $\mathrm{SiO}_{2}$ and $\mathrm{CaCO}_{3}$ films are affected by the migration and precipitation of soluble species during drying. Dilute dispersions were dried in a small chamber with welldefined wetting characteristics. Electron microscopy studies and chemical analysis showed that the soluble polymer carboxymethylcellulose (CMC) is carried with the solvent to the drying front. The polymer concentration is highest in the centre of the dried colloidal film and decreases towards the edges. It is interesting to note that the colloidal films of monodisperse silica spheres displayed a high degree of structural order despite a high concentration of CMC. This suggests that any depletion induced interparticle attraction is insufficient to affect the assembly of the densely packed colloidal crystals.

The $\mathrm{CaCO}_{3}$ particles are slightly soluble in water and the dissolved species reprecipitate in the centre of a drying dispersion due to convective transport to the drying front. The morphology of the reprecipitated $\mathrm{CaCO}_{3}$ varies from rod-like to equiaxial, which was related to the specific interaction of the $\mathrm{Ca}^{2+}$ ions with the organic additives. The re-precipitation of rod-like particles could be related to the adsorbed poly(acrylic acid) on the surface of the as-received powder that acts as the nucleation sites. We suggest that the relatively slow evaporation-driven increase in the concentration of the dissolved $\mathrm{CaCO}_{3}$ favours slow nucleation and subsequent crystal growth from a single nucleation site. Addition of the soluble polymer CMC to the $\mathrm{CaCO}_{3}$ suspensions results in a CMC-rich zone in the centre of the dried film. There was no evidence of reprecipitated rod-like $\mathrm{CaCO}_{3}$ particles in the presence of CMC. This was attributed to the complexation of $\mathrm{Ca}^{2+}$ with the anionic CMC in solution, which limits the possibility of the formation of distinct crystal shapes.

\section{Acknowledgments}

The authors are grateful to Dr. Nigel Sanders of Specialty Minerals for providing the $\mathrm{CaCO}_{3}$ powder. This work is a part of the Surface Treatment Research Programme at Karlstad University. The financial support from the Swedish Pulp and Paper Research Foundation, the Foundation for Knowledge and Competence Development and the Swedish Agency for Innovation Systems (VINNOVA) is gratefully acknowledged.

\section{References}

[1] P.H.F. Hansen, S. Rödner, L. Bergström, Langmuir 17 (2001) 4867.

[2] R. Aveyard, J.H. Clint, D. Nees, Colloid Polym. Sci. 278 (2) (2000) 155.

[3] S.C. Rödner, P. Wedin, L. Bergström, Langmuir 18 (2002) 9327.

[4] C.D. Dushkin, G.S. Lazarov, S.N. Kotsev, H. Yoshimura, K. Nagayama, Colloid Polym. Sci. 177 (1999) 914.

[5] A.S. Dimitrov, K. Nagayama, Langmuir 12 (1996) 1303.

[6] R. Micheletto, H. Fukuda, M. Ohtsu, Langmuir 11 (1995) 3333.

[7] S. Maenosono, C. Dushkin, Y. Yamaguchi, Colloid Polym. Sci. 277 (1999) 993.

[8] P.A. Kralchevsky, K. Nagayama, Adv. Colloid Interface Sci. 85 (2000) 145.

[9] G.W. Scherer, D.R. Uhlmann, D.R. Ulrich (Eds.), Ultrastructure Processing of Advanced Materials, Wiley, New York, 1992, pp. 179199.

[10] K.P. Velikov, C.G. Christova, R.P.A. Dullens, A. van Blaaderen, Science 296 (5565) (2002) 106.

[11] G.W. Scherer, J. Am. Ceram. Soc. 73 (1) (1990) 3.

[12] J.J. Guo, J.A. Lewis, J. Am. Ceram. Soc. 82 (9) (1999) 2345.

[13] P.C. Hidber, T.J. Graule, L.J. Gauckler, J. Am. Ceram. Soc. 78 (7) (1995) 1775.

[14] H.P. Huinink, L. Pel, M.A. Michels, J. Phys. Fluids 14 (4) (2002) 1389. 
[15] S. Lampenscherf, W. Pompe, D.S. Wilkinson, J. Am. Ceram. Soc. 83 (6) (2000) 1333.

[16] P. Wedin, C.J. Martinez, J.A. Lewis, J. Daicic, L. Bergström, J. Colloid Interface Sci. 272 (1) (2004) 1.

[17] P.A.C. Gane, J.J. Hooper, A. Grunwald, TAPPI J. 80 (2) (1997) 109.

[18] P. Lepoutre, D. Lord, J. Colloid Interface Sci. 134 (1) (1990) 66.

[19] C. Kugge, Consolidation and Structure of Paper Coating and Fibre Systems, PhD thesis, Royal Institute of Technology, Stockholm, 2003.

[20] E.D. Cohen, E.B. Gutoff (Eds.), Modern Coating and Drying Technology, VCH, New York, 1992, pp. 267-298.

[21] A.F. Routh, W.B. Russel, Langmuir 15 (22) (1999) 7762.

[22] G.N. Howatt, R.G. Breckenridge, J.M. Brownlow, J. Am. Ceram. Soc. 30 (8) (1947) 237.

[23] J.A. Lewis, K.A. Blackman, A.L. Ogden, J.A. Payne, L.F. Francis, J. Am. Ceram. Soc. 79 (12) (1996) 3225.

[24] M.J. Snowden, S.M. Clegg, P.A. Williams, I.D. Robb, J. Chem. Soc. Faraday Trans. 87 (14) (1991) 2201

[25] M.J. Snowden, P.A. Williams, M.J. Garvey, I.D. Robb, J. Colloid Interface Sci. 166 (1) (1994) 160.

[26] D.R. Lide (Ed.), CRC Handbook of Chemistry and Physics, 73rd ed., CRC Press, Boca Raton, FL, 1992.

[27] R.D. Deegan, O. Bakajin, T.F. Dupont, G. Huber, S.R. Nagel, T.A Witten, Nature 389 (1997) 827.

[28] J.A. Payne, Stress Evolution in Solidifying Coatings, PhD thesis, University of Minnesota, 1998.

[29] L.F. Francis, A.V. McCormick, D.M. Vaessen, J.A. Payne, J. Mater. Sci. 37 (22) (2002) 4717
[30] S.G. Croll, J. Appl. Polym. Sci. 23 (1979) 847.

[31] S.G. Croll, J. Coat. Technol. 51 (648) (1979) 64.

[32] N.D. Denkov, O.D. Velev, P.A. Kralchevsky, I.B. Ivanov, H. Yoshimura, K. Nagayama, Langmuir 8 (1992) 3183.

[33] S. Asakura, F. Oosawa, J. Polym. Sci. 33 (1958) 183.

[34] C.W. Hoogendam, J.C.W. Peters, R. Tuinier, A. de Keizer, M.A.C. Stuart, B.H. Bijsterbosch, J. Colloid Interface Sci. 207 (2) (1998) 309.

[35] B. Siffert, P. Fimbel, Colloids Surf. 11 (3-4) (1984) 377.

[36] K.R. Rogan, A.C. Bentham, I.A. George, D.R. Skuse, Colloid Polym. Sci. 272 (10) (1999) 1175.

[37] H. Cölfen, L.M. Qi, Chem. Eur. J. 7 (1) (2001) 106.

[38] H. Kawaguchi, H. Hirai, K. Sakai, S. Sera, T. Nakajima, Y. Ebisawa, K. Koyama, Colloid Polym. Sci. 270 (12) (1992) 1176.

[39] N. Hosoda, T. Kato, Chem. Mat. 13 (2) (2001) 688.

[40] K. Naka, Y. Chujo, Chem. Mater. 13 (10) (2001) 3245.

[41] D. Verdoes, D. Kashchiev, G.M. Vanrosmalen, J. Cryst. Growth 118 (3-4) (1992) 401.

[42] G. Xu, N. Yao, I.A. Aksay, J.T. Grove, J. Am. Chem. Soc. 120 (46) (1998) $11,977$.

[43] S.K. Zhang, K.E. Gonsalves, Langmuir 14 (23) (1998) 6761.

[44] J. Rieger, J. Thieme, C. Schmidt, Langmuir 16 (22) (2000) 8300.

[45] J. Rieger, Tenside Surfact. Deterg. 39 (6) (2003) 221 